The heat of solution is independent of the concentration when this is less than about 0.3 molal.

6. Pure $\beta$-anhydrous milk-sugar has been prepared by an improved method of slow crystallization, and a delicate test shows that it is free from hydrate. Its specific gravity at $20^{\circ}$ is 1.59 , that of the hydrate being I.54.

7. The present data on the heats of solution confirm quantitatively the view that the crystalline substance which alcohol and ether precipitate from cold stable milk-sugar solutions is not a pure substance as was first supposed but is a mechanical mixture of the hydrate and the $\beta$-anhydride. It does not show mutarotation when redissolved in water because the two substances are present in it in the same proportions approximately in which they occur in stable solutions.

8. When the temperature of a stable solution of milk-sugar is suddenly changed a slight thermal lag is observed in its rotatory power, which indicates that the hydration is slightly increased with rise of temperature between $0^{\circ}$ and $100^{\circ}$. The direction and magnitude of this lag agree with the conclusions drawn from the observed value of the heat of passage.

9. The final heat of solution of hydrated milk-sugar is calculated from the solubilities at $15^{\circ}$ and $25^{\circ}$ to be -II.5, agreeing with the calorimetric measurement at $20^{\circ}$, which gives -11.4 .

UYIVERSITY OF ILLINOIS,

URBANA. ILL.

\title{
A NEW INSTRUMENT FOR REDUCING GAS VOLUMES TO STANDARD CONDITIONS.
}

BX GRANT T. DAVIS.

Received April 1, rgo8.

The necessity for making a considerable number of accurate measurements of gas volumes has led to the working out of the following device ior their reduction to standard volume. Since all that is necessary for the physical reduction of a gas to standard volume, is to subject it to a definite pressure, a water column of variable length was first tried, but this was discarded in favor of a column of known length with a fixed scale. The length of the column of mercury $\left(\mathrm{L}_{m}\right)$ necessary to compress a gas to standard volume at temperature " $t$ " is found by the formula, $\mathrm{V}=\frac{v(p-p \text { ' }}{760(\mathrm{I}+a t)}$. the conditions being such that $v=\mathrm{V}$; then $p=760(\mathrm{r}+a t)+p^{\prime}$ and $\mathrm{L}_{\mathrm{m}}=$ $p-760$. The length for the water column was taken as $\mathrm{L}_{m} \times 13.59$, and correction was made for the expansion of water with rise in temperature.

The apparatus for use with gases which can be collected over water consists of a piece of iron pipe about two meters long, fitted with a $T$ near the top and an elbow at the lower end. The elbow is closed by a rubber 
stopper carrying a glass $\mathrm{T}$, one arm of which is fitted with a stopcock, and the other connected to the water supply. The T at the upper end of the pipe carries a small reservoir at the top to prevent overlow in case of too hasty filling, and the side-opening is closed by a rubber stopper carrying

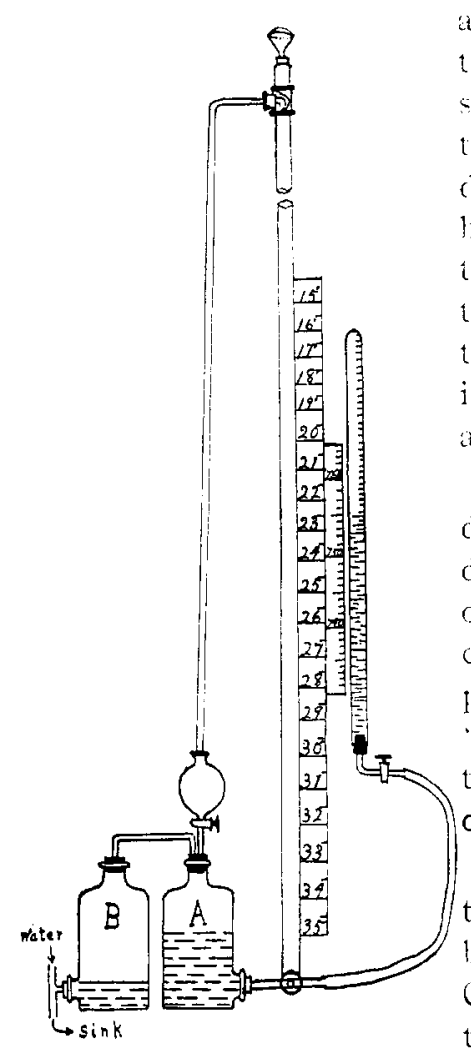

a siphon with a very short inner leg, and the long leg emptying into the sink, or as shown in the figure. To the lower part of the pipe is attached a scale, so graduated in degress that the column of water from the bottom of the short leg of the siphon to the sraduation is the calculated length for the tenperature represented by the graduation. Atached to this "temperature" scale, is a sliding "pressure" sale whose divisions ane $13.6 \mathrm{~mm}$. long.

To aroid the error which would be introduced by using tap water of a temperature diffetent from that of the room, the system of bottes "A" " $B$ " is introduced. "A" contains distilled water at the room temperature. Tap water being admitted to "13," the water from " $A$ " is forced into the apparatus, and no temperature change occurs.

To lise the apparatus the burette containing the gas is connected to the $\mathrm{T}$ at the bottom of the pipe and the stopcock opened. Care must be taken that there is no air in the connecting tube. The graduation 760 on the pressure scale is placed opposite that point on the temperature scale which corresponds to the observed temperature, water is admitted to the pipe until the siphon begins to act, and while a slow stream continues to flow, the meniscus in the burette is brought level with that graduation of the pressure scale which corresponds to the observed barometric pressure, and the corrected volume of the gas read off. The position represented in the figure is that for a gas observed at a temperature of $21.4^{\circ}$, and barometric pressure of $754 \mathrm{~mm}$.

Table "A" gives the length of water column necessary to compress a gas to the standard volume for temperatures from $15{ }^{\circ}$ to $34^{\circ}$. Table "B" offers a comparison between the standard volume as calculated, and as observed by means of this instrument. 




\section{A LECTURE TABLE DOWN-DRAFT.}

BY WM. L. DUDLEY.

Received March 26, Ig08.

A powerful and reliable down-draft on a lecture table is of great service and is much superior to a hood behind the lecturer since by its use experiments with the most disagreeable and poisonous gases can be made safely in full view of the audience.

My experience in the past has been that such down-drafts are rare, in fact, I have never had one that was usable until I installed in the lecture theatre of Furman Hall, the new chemical laboratory, the arrangement herein described.

The requirements of a good down-draft are (I) certainty of action regardless of the weather or temperature, (2) sufficient suction to permit of moderate freedom of action on the part of the experimenter which is not possible if the air current is so slow as to require a closed chamber to prevent the escape of gases into the room, (3) the draft tube with its cover being so arranged that it can be located in or near the center of the lecture table flush with the table top so as to offer no obstruction, and (4) a cover to the draft tube which will not stick nor become fast from corrosion. 